\title{
Quality of acute stroke care in a regional Victorian hospital, Australia
}

TW Wilson Yang, MBBS, PG Dip (Surg Anat) ${ }^{1^{\star}}$, Md Rafiqul Islam, MBBS, MPH, Ph.D..$^{1,2,3,4}$

${ }^{1}$ Goulburn Valley Health, Graham St, Shepparton, Victoria 3630, Australia

${ }^{2}$ Department of Rural Health, the University of Melbourne, Shepparton, Victoria 3630,

Australia

${ }^{3}$ School of Health and Social Development, Deakin University, Burwood, Victoria, Australia

${ }^{4}$ Rumbalara Aboriginal Cooperative Limited, Wyndham St, Shepparton, Victoria 3630,

Australia

\section{Running Head/Short Title}

A regional Australian hospital's stroke care quality

Number of tables included: 4

Abstract word count: 245 (excluding the paragraph headings)

Number of words in main text: 1969 (excluding abstract, tables and references)

\section{"Corresponding Author:}

Dr Tze Wei (TW) Wilson Yang

MBBS, PG Dip (Surgical Anatomy)

2307/231 Harbour Esplanade

Docklands VIC 3008

$\mathrm{T}:+61(0) 433990506$

F: +61 358322394 (Attn: Dr Md Rafiqul Islam)

E: wilyang.tw@gmail.com

Keywords: Rural health, rural health services delivery, safety and quality, service evaluation, acute stroke care

Acknowledgements: We acknowledge the contribution of the data custodian and Health Information Management Department at Goulburn Valley Health for providing the data.

Conflicts of interest: The authors declare no conflicts of interest.

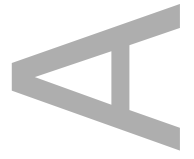

This is the author manuscript accepted for publication and has undergone full peer review but has not been through the copyediting, typesetting, pagination and proofreading process, which may lead to differences between this version and the Version of Record. Please cite this article as doi: 10.1111/ajr.12491

This article is protected by copyright. All rights reserved 
Article type, : Original Research
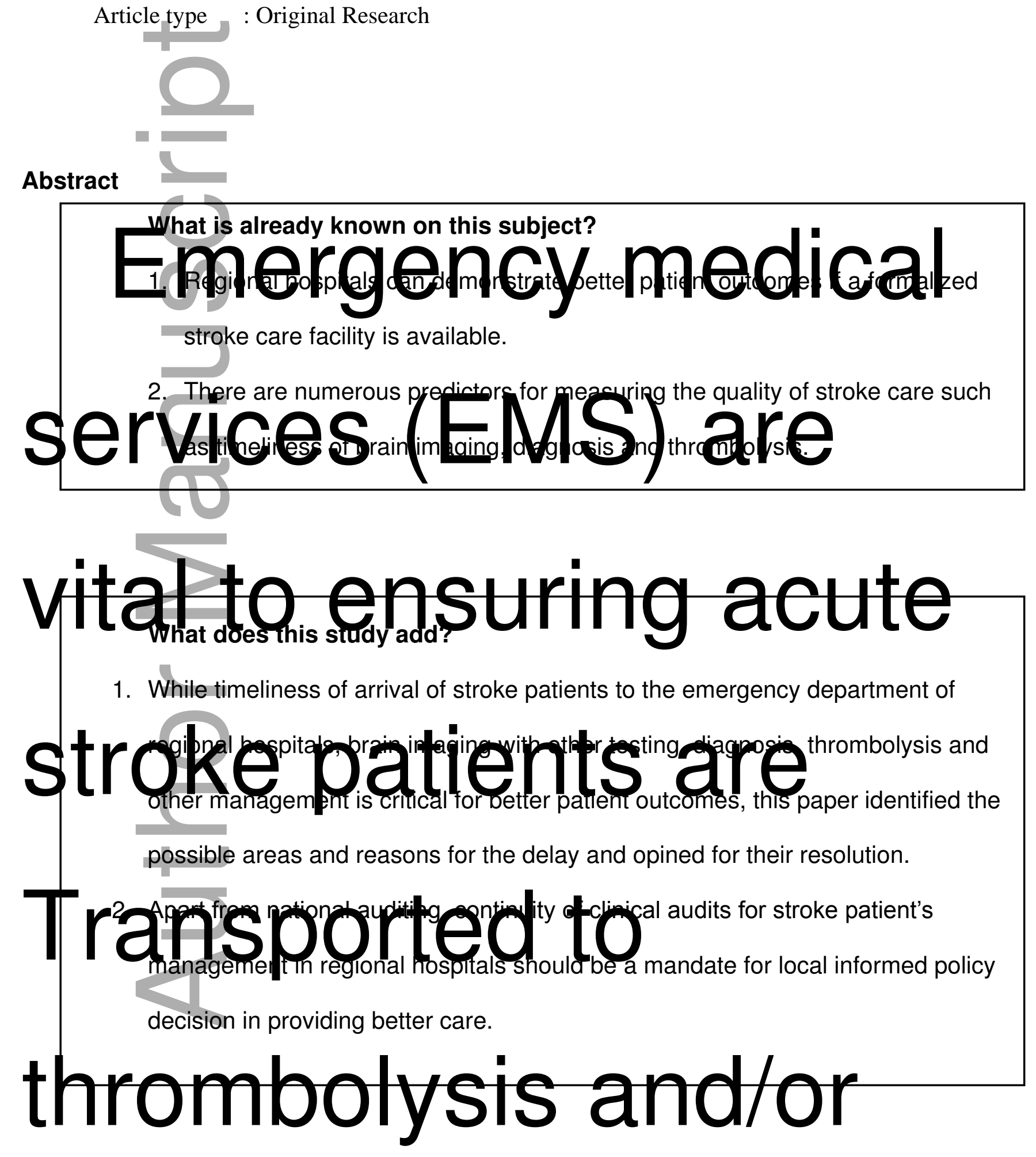

This article is protected by copyright. All rights reserved 
stroke unit centres.

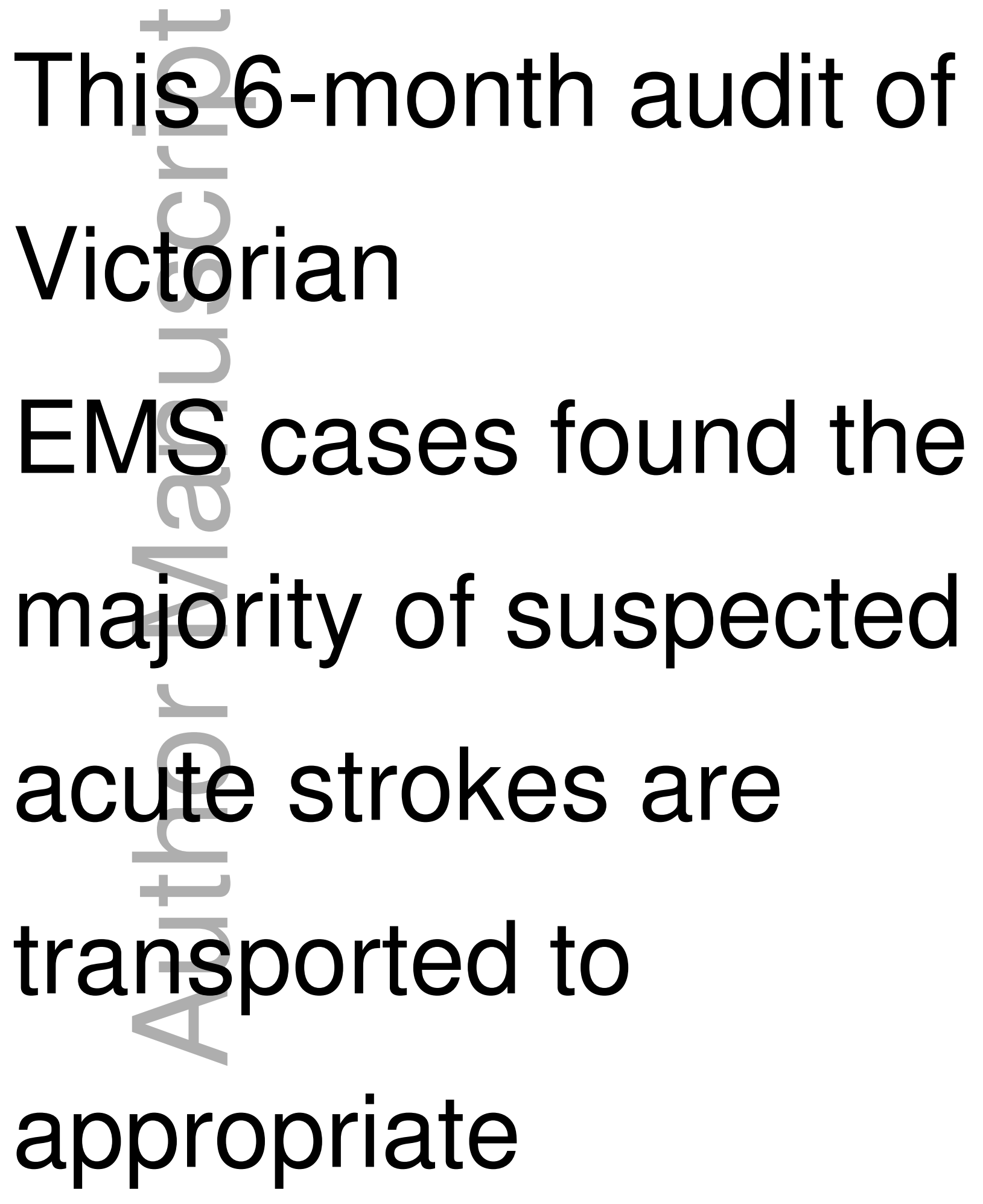

This article is protected by copyright. All rights reserved 


\section{Stroke centres.}

However, there is still

room for improvement,

in particular, strategies

to $\geq$

Improve access to

stroke services in some

rural regions and to 


\section{ensure}

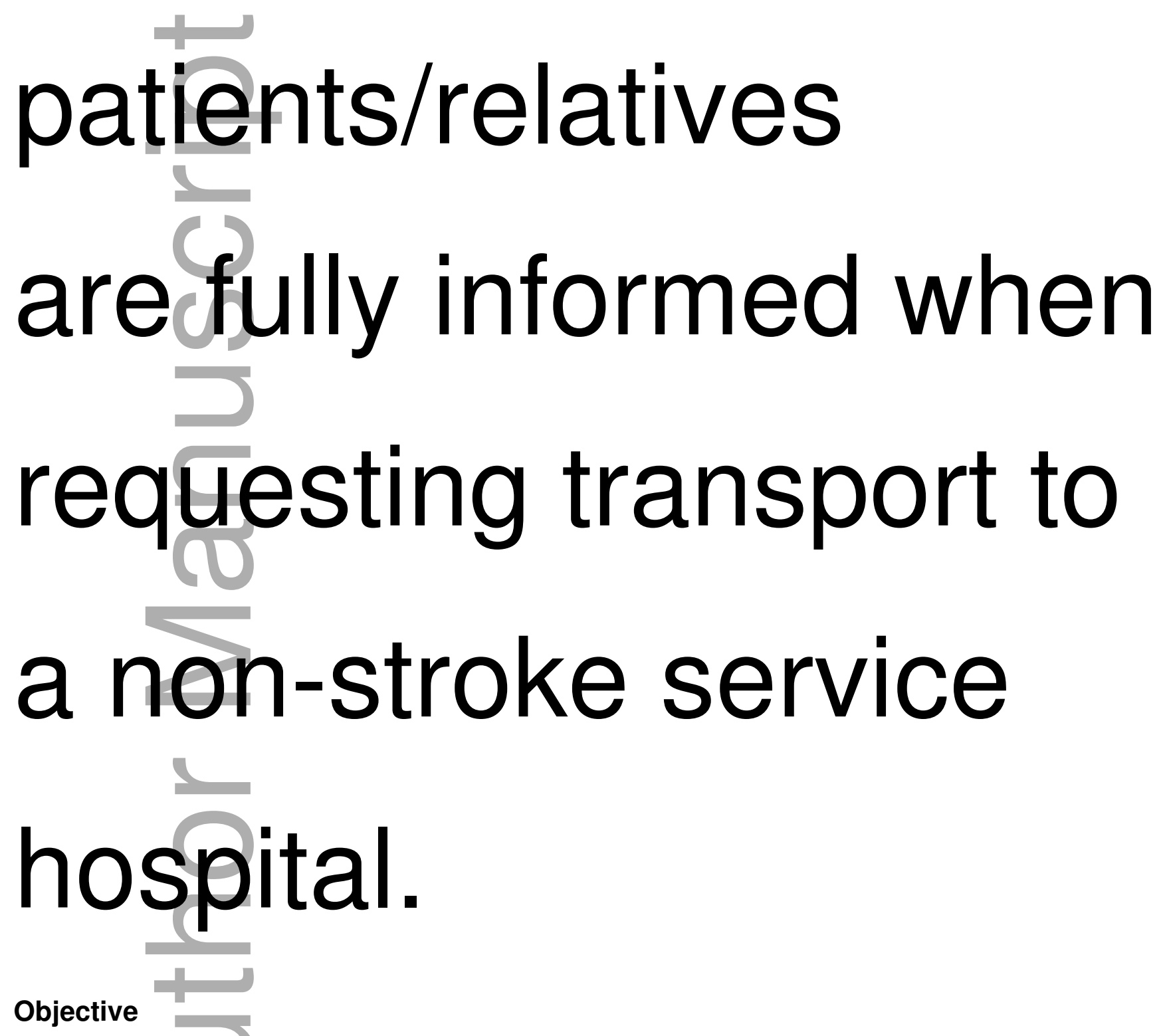

The quality of acute stroke care in a regional Victorian Hospital (study hospital) was assessed by comparing with selected standard indicators of Acute Stroke Clinical Care.

Design

A retrospective review of stroke patients' records was performed manually and by reviewing electronic database.

Setting 
The study was carried out in Goulburn Valley Health, one of five regional referral and teaching hospitals in Victoria, Australia.

\section{Participants}

Stroke patients who were discharged from the study hospital between October 2015 and March 2016.

\section{Main outcome measures}

Timeliness of brain imaging, proportion of patients thrombolysed if arrived within 4.5 hours of stroke and timeliness of thrombolysis.

\section{Results}

A total of 66 patients' records were found. Brain imaging was completed for $45 \%$ compared to $25.8 \%$ nationally if arrived to the study hospital within one hour of stroke, and $100 \%$ imaging completed within 24 hours of arrival compared to $75.6 \%$ nationally. When patients arrived to the Emergency Department within 4.5 hours of stroke, $37.5 \%$ (23.6\% nationally and $18.6 \%$ in similar sized hospitals) of them were thrombolysed; while none were thrombolysed within 60 minutes of arrival. Door to thrombolysis time was 85 minutes (IQR 79-86), seven minutes longer than national standard. Symptoms onset to thrombolysis time was 225 minutes (IQR 195-240), 55 minutes longer than national standard.

\section{Conclusion}

The timeliness of brain imaging and thrombolysis were comparable in the study hospital to that of the national standard while other stroke management indicators still require improvement. Continuing efforts for improvement and revisiting possible areas of delay are warranted.

Keywords: Rural health, rural health services delivery, safety and quality, service evaluation, acute stroke care

\section{Introduction}

Stroke is the leading cause of acquired disability globally and the second most common cause of death in developed countries (1). Care for these patients should be in accordance with 
evidence-based guidelines (2). There are substantial differences in acute stroke care between low to middle income and high income countries (3). Therefore, monitoring of the quality of stroke care has great relevance (4). Despite many hospitals in the middle and high income countries providing advanced care for stroke patients, there are variabilities in organization and treatment of stroke patients (5). There is a large quality gap between metropolitan and nonmetropolitan areas in stroke care and this could be addressed partly through procedural efforts improvement and by increasing availability of neurological services (6). Moreover, poor access to stroke specialist care in regional areas may limit the rapid assessment and diagnosis of acute stroke (7). A study demonstrated that organizational systematic approach and services maintenance could improve the stroke patient's outcomes and reduce the disease burden (8). In Australia, stroke is one of the biggest killers with an estimated 56,000 new and recurrent strokes in 2017 (9) and this number may continue to increase in the coming years. With the availability of formalized stroke care, regional hospitals can provide better patient outcomes (10). However, reduction of treatment delay and accuracy of selecting patients for thrombolysis still remain as important factors for quality improvement in acute stroke care (11).

With the release of the National Stroke Clinical Audit Report 2015 (12), it is extremely important to assess how regional hospitals have performed for selected indicators of recommended acute stroke care. The quality of acute stroke care in the study hospital can be determined by comparing selected Australian Commission on Safety and Quality in Health Care (ACSQHC) Acute Stroke Clinical Care Standard Indicators against the national standard and other hospitals with similar patient volume. In this study, a retrospective audit of data for a period of six months between October 2015 and March 2016 was conducted in a regional Victorian hospital to demonstrate the timeliness of management of acute stroke by looking at some of the stroke management indicators including that of brain imaging and thrombolysis, and compare them to that of national data and data from similar hospitals.

\section{Methods}

This study was conducted in a regional Victorian hospital, Australia. All patients discharged with a final principal diagnosis of stroke over a 6 month period from $1^{\text {st }}$ October 2015 to $31^{\text {st }}$ March 2016 were identified and included. The study met the institutional criteria for conducting this as a clinical audit and received an approval from the Goulburn Valley Health Human Research Ethics Committee.

This article is protected by copyright. All rights reserved 
Data for the stroke patients were obtained from hospital's Health Information Services. Scanned clinical records during the initial presentation of the patients to the Emergency Department (ED) were reviewed and following data were collected:

- Patient's arrival time to hospital

- Patient's estimated time of stroke from ambulance case sheet or from initial assessment notes.

- Patient's time of brain imaging from arrival to ED

Patient's thrombolysis time information regarding timeliness of brain imaging and timeliness of thrombolysis in all hospitals on a national level was obtained from the National Stroke Audit Acute Services Report 2015 (12).

Timeliness of thrombolysis information in hospitals of similar patient volume was taken from National Stroke Audit Acute Services Supplement 2015 (13). All the data above were collected and collated into a spreadsheet using MS Excel 2016.

\section{Statistical analysis}

Data were analysed in MS Excel 2016. Patient's data were cross-checked with data obtained from Nurse Unit Manager and the study hospital's Health Information Services for discrepancies. Timeliness of brain imaging from arrival to the ED was compared to the national data. Also, the timeliness of thrombolysis from arrival to the ED was compared to that of national level as well as with other hospitals of similar patient volume. Summary statistics were presented in tabulated form using the actual observation, proportion, median and interquartile ranges.

\section{Results}

During the data reviewing period from $1^{\text {st }}$ October 2015 to $31^{\text {st }}$ March 2016, there were a total of 66 patients diagnosed with acute stroke. Of the 66 patients, $45.5 \%(n=30)$ patients were classified as ischaemic stroke, $21.2 \%(n=14)$ as intracerebral hemorrhagic stroke and the remaining $33.3 \%(n=22)$ as indeterminate stroke (Table 1$)$.

We found that $45.5 \%(n=30)$ patients received brain imaging within an hour of arrival and all 66 patients received brain imaging within 24 hours of arrival to the ED. The median time of brain imaging from arrival to the ED was 96 minutes (IQR 39-149). Contrary to our findings, national data showed that $25.8 \%$ (1055 out of 4087 ) patients and $75.6 \%$ (3090 out of 4087 ) patients received brain imaging within 1 hour and 24 hours of arrival to the ED, respectively. After 
combining all data, the median time of brain imaging from arrival to the ED at the national level was 92 minutes (IQR 46-185) (Table 2).

Out of 30 patients that classified as ischaemic stroke, only $26.7 \%(n=8)$ arrived within 4.5 hours of the onset of stroke symptom. The other $73.3 \%(n=22)$ ischaemic stroke patients who did not arrive within 4.5 hours of the onset of symptoms were either due to long travelling time to the hospital or they delayed seeking medical attention including the delay in notifying the ambulance. Of the patients who arrived at hospital within 4.5 hours of stroke symptoms, $37.5 \%$ $(n=3)$ received thrombolysis, although not within 60 minutes of arrival. The median time taken from arrival to the hospital ED to the time of thrombolysis was 85 minutes (IQR 79-86). The median time taken from the onset of stroke symptoms to thrombolysis was 225 minutes (IQR 195-240).

The national level data indicated that $23.6 \%$ patients received thrombolysis if they arrived within 4.5 hours of stroke symptom onset and $25.5 \%$ patients were thrombolysed if they arrived to the hospital within 60 minutes of stroke symptoms. Median time of thrombolysis from arrival to the hospital at national level was 78 minutes. Overall, the median time taken from stroke symptom onset to thrombolysis was 170 minutes (IQR 123-219) at national level. Data from hospitals with similar patient volume showed that $18.6 \%$ patients received thrombolysis if they arrived within 4.5 hours of stroke symptom onset and $14.5 \%$ patients had thrombolysis within 60 minutes of arrival to those hospitals (Table 3 ).

To understand further, the time from arrival at the ED to thrombolysis (door-to-thrombolysis time) were divided into 3 different categories: door to CT time, CT to CT report time and CT report to initiation of thrombolysis time. The median time (IQR) for these categories were, 48 (37.5-49), 20 (17.5-25) and 21 (13-24.5) minutes, respectively (Table 4).

\section{Discussion}

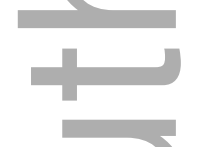

This study demonstrated a higher proportion of patients received brain imaging within an hour of admission to the study hospital compared to the national data. Since ischaemic stroke occurs when blood supply in a cerebral vascular territory is critically compromised, it is extremely important for timely diagnosis of ischaemic stroke. Brain imaging with an appropriate interpretation in a shortest possible time is important for a comprehensive decision for a better 
patient outcome. The typical patient loses 1.9 million neurons every minute if ischaemic stroke left untreated (15), hence the timeliness of brain imaging is not only critical for the diagnosis, but also important for early intervention to minimize post stroke consequences. In this study, we observed that the study hospital well exceeded that of national data for brain imaging who presented to the hospital within an hour of onset of stroke symptoms.

The study showed a higher proportion of patients (37.5\%) received thrombolysis when compared to national standard $(23.6 \%)$ and other hospitals of similar patient volume $(18.6 \%)$ where the patient arrived within 4.5 hours of stroke symptoms. On the other hand, $62.5 \%$ of the patients who arrived in the study hospital within 4.5 hours of stroke symptoms did not received thrombolysis due to increased risk of bleeding, delay in decision-making by the patient or next-of-kin, clinical acumen of the neurologist and uncertainty of the neurologist in determining the type of stroke. However, the proportion of patients who received thrombolysis within 60 minutes of arrival in the study hospital (0\%) was substantially lower than the national standard $(25.5 \%)$ as well as other hospitals with similar patient volume (14.5\%). When combining the data in the study hospital, median door to thrombolysis time was 7 minutes longer than the national standard, and time from symptoms onset to thrombolysis was 55 minutes longer compared to the national data.

Based on the further breakdown of door-to-thrombolysis time in Table 4, a few areas were identified to improve the timeliness of thrombolysis. Firstly, the location of the CT machine; 'door to CT' time would be quicker if the CT facilities are positioned within or closer to the ED, given that the space requirement guidelines are met (16). Secondly, the CT machine could be kept stand-by. This would allow the X-ray tube in the CT machine to start working immediately when required. Typically, the CT machine is switched off to help protect its components and extends lifespan (17). The X-ray tube routinely takes considerable time to warm-up if switched off: 3 minutes from 'power-on' to 'ready to warm-up' and another 6 minutes to perform detector calibrations (18). In the event that a patient with an acute ischaemic stroke arrives at the ED overnight, it would take approximately 9 minutes for the CT machine to be ready for use. Therefore, keeping the CT machine on stand-by overnight and ensuring that its detector calibration has been performed at least once in the last 24 hours will ensure that it is ready to use immediately. Lastly, after the CT report has confirmed the diagnosis of acute ischaemic stroke, there tends to be a delay in administering thrombolysis as time would be required to 
explain the procedure, risk and benefits to the patient or their next-of-kin. This delay can be minimized with the provision of handouts about stroke (19) and thrombolysis (20) to patients and their next-of-kin prior to the CT report being finalized.

Overall, the quality of acute stroke care in the study hospital based on timeliness of brain imaging and timeliness of thrombolysis is on par with the national standard. Continuing quality improvement activities including identification of possible areas of delays and their respective targeted changes will ultimately improve acute stroke patient care.

There are some potential limitations in this study, such as confirmation of stroke diagnosis. About a third of all stroke patients that attended in the study hospital were classified as indeterminate type. Routinely, a normal CT of brain was observed in many ischaemic stroke cases (14). Since World Health Organization defined stroke as a clinical syndrome, therefore, stroke types that were classified as indeterminate or unknown in this study, many of them might be ischaemic stroke cases.

In addition, only $37.5 \%(3 / 8)$ of ischaemic stroke patients underwent thrombolysis between October 2015 and March 2016. Conclusions drawn from this smaller sample size might not be appropriate. Morevoer, this study only takes into consideration two of the ACSQHC Acute Stroke Clinical Care Standard Indicators that may not be adequate for comparing overall quality. However, the timeliness of brain imaging and thrombolysis data of the study hospital adds much value to the current body of evidence and addresses the concerns regarding stroke care quality gap in regional hospitals. . Moreover, the findings may assist other regional hospitals for planning at organizational level to improve stroke patient care.

It would be worthwhile to conduct assessments of the quality of acute stroke care together with other regional hospitals. Assessment of all the ACSQHC acute stroke clinical care standard indicators over a longer period and compare them against the new National Stroke Clinical Audit (21) would assist in adopting a better informed policy decision for a uniform acute stroke management in regional hospitals.

This article is protected by copyright. All rights reserved 


\section{References}

1. World Health Organization. Global Health Estimates 2016: Deaths by Cause, Age, Sex, by Country and by Region, 2000-2016. Geneva: World Health Organization, 2018.

2. Wiedmann S, Heuschmann PU, Hillmann S, Busse O, Wietholter H, Walter GM, et al. The quality of acute stroke care- an analysis of evidence-based indicators in 260000 patients. Deutsches Arzteblatt international. 2014;111(45):759-65.

3. Baatiema L, de-Graft Aikins A, Sav A, Mnatzaganian G, Chan CKY, Somerset S. Barriers to evidence-based acute stroke care in Ghana: a qualitative study on the perspectives of stroke care professionals. BMJ open. 2017;7(4):e015385.

4. Di Carlo A, Accetta G, Bellan M, Terni G, Lamassa M, Facchini R, et al. Quality indicators in acute stroke care: a prospective observational survey in 13 Italian regions. Aging clinical and experimental research. 2014;26(3):279-86.

5. Munoz Venturelli P, Robinson T, Lavados PM, Olavarria VV, Arima H, Billot L, et al. Regional variation in acute stroke care organisation. Journal of the neurological sciences. 2016;371:126-30.

6. Seabury S, Bognar K, Xu Y, Huber C, Commerford SR, Tayama D. Regional disparities in the quality of stroke care. The American journal of emergency medicine. 2017;35(9):1234-9.

7. Bagot KL, Cadilhac DA, Hand PJ, Vu M, Bladin CF. Telemedicine expedites access to optimal acute stroke care. Lancet. 2016;388(10046):757-8.

8. Ruland S, Gorelick PB, Schneck M, Kim D, Moore CG, Leurgans S. Acute stroke care in Illinois: a statewide assessment of diagnostic and treatment capabilities. Stroke. 2002;33(5):1334-9.

9. Hoffbrand R. Stroke. 7 ed. McGrath E, Canavan M, O'Donnell M, editors. Philadelphia, PA: Elsevier Inc; 2017.

10. McCann L, Groot P, Charnley C, Gardner A. Excellence in regional stroke care: an evaluation of the implementation of a stroke care unit in regional Australia. The Australian journal of rural health. 2009;17(5):273-8.

11. Lau AHT, Hall G, Scott IA, Williams M. Thrombolysis in acute stroke: ongoing challenges based on a tertiary hospital audit and comparisons with other Australian studies. 
Australian health review : a publication of the Australian Hospital Association. 2016;40(1):43-53.

12. National Stroke Foundation. National Stroke Audit Melbourne: National Stroke Foundation, 2015.

13. National Stroke Foundation. National Stroke Audit Melbourne: 2015.

14. Caplan L. Caplan's stroke: a clinical approach. 4 ed. Philadelphia, PA: Saunders; 2009.

15. Saver JL. Time is brain--quantified. Stroke. 2006;37(1):263-6.

16. Siemens Healthineers. Siemens SOMATOM Definition Edge - typical final drawing set. https://ftpsiemensmedicalcom/pp-typicals/CT/Definition\%20Edge/PDF\%20File/12032pdf.

17. Kunzel $U$. Siemens presents new 16-slice CT scanner Somatom Scope. Erlangen: 2014.

18. (CEP) CfEbP. 128 to 320 slice CT scanner technical specifications. 2009 Contract No.: CEP 08028.

19. Better Health Channel. Stroke Victoria, Australia: Department of Health \& Human Services. 2015.

20. Surgery ANŻSfV. Thrombolysis, Australia. 2017.

21. Stroke Foundation Victoria. InformMe. Stroke data 2017 [10/02/2018]. Available from: https://informme.org.au/stroke-data.

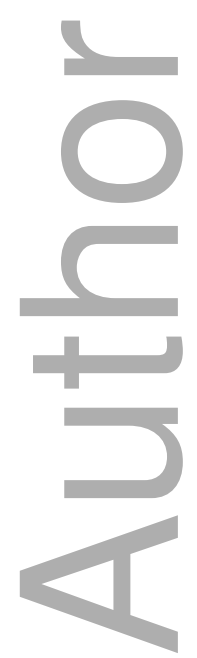


Table 1: Different types of stroke frequency in the study hospital $(N=66)$

\begin{tabular}{|c|c|}
\hline Type of stroke & Frequency, $\mathbf{n}(\%)$ \\
\hline Ischaemic & $30(45.5 \%)$ \\
\hline Intracerebral haemorrhage & $14(21.2 \%)$ \\
\hline Indeterminate/Unknown & $22(33.3 \%)$ \\
\hline
\end{tabular}

Table 2: Time required for brain imaging in the study hospital and at National level

\begin{tabular}{|c|c|c|}
\hline Indicators & $\begin{array}{c}\text { Study Hospital, N=66 } \\
\mathbf{n}(\%)\end{array}$ & $\begin{array}{c}\text { National, N=4087 } \\
\mathbf{n}(\%)\end{array}$ \\
\hline $\begin{array}{c}\text { Brain imaging within 1 } \\
\text { hour of arrival }\end{array}$ & $30(45.5 \%)$ & $1055(25.8 \%)$ \\
\hline $\begin{array}{c}\text { Brain imaging within 24 } \\
\text { hours of arrival }\end{array}$ & $66(100 \%)$ & $3090(75.6 \%)$ \\
\hline $\begin{array}{c}\text { Median time of brain scan } \\
\text { from arrival to ED (IQR) }\end{array}$ & 96 minutes (39-149) & 92 minutes (46-185) \\
\hline
\end{tabular}

Table 3: Comparison of reperfusion for acute ischaemic stroke at different levels

\begin{tabular}{|c|c|c|c|}
\hline $\begin{array}{c}\text { Indicators } \\
\text { Received } \\
\text { thrombolysis if } \\
\text { arrived within } 4.5 \\
\text { hours of stroke } \\
\text { symptom onset }\end{array}$ & 3 of $8(37.5 \%)$ & 198 of $837(23.6 \%)$ & $\begin{array}{c}\text { Nospitals with } \\
\text { similar patient } \\
\text { volume }\end{array}$ \\
\hline Thrombolysis within & 0 of 3 (0\%) & 59 of $231(25.5 \%)$ & 7 of $48(14.5 \%)$ \\
\hline
\end{tabular}




\begin{tabular}{|c|c|c|c|}
\hline $\begin{array}{c}60 \text { minutes of } \\
\text { hospital arrival }\end{array}$ & & \\
\hline $\begin{array}{c}\text { Median door to } \\
\text { thrombolysis (IQR) }\end{array}$ & 85 minutes (79-86) & $\begin{array}{c}78 \text { minutes (Not } \\
\text { available) }\end{array}$ & - \\
\hline $\begin{array}{c}\text { Median time from } \\
\text { onset to thrombolysis } \\
(\mathrm{IQR})\end{array}$ & 225 minutes (195- & 170 minutes (123- & \\
\hline
\end{tabular}

Table 4: Break-down of 'door-to-needle' time for acute ischaemic stroke patients who received thrombolysis in the study hospital [October 2015 - March 2016]

\begin{tabular}{|c|c|c|c|}
\hline $\begin{array}{c}\text { Indicator } \\
\text { (October 2015 } \\
\text { March 2016) }\end{array}$ & $\begin{array}{c}\text { Door to CT time } \\
(\text { IQR) }\end{array}$ & $\begin{array}{c}\text { CT to CT report } \\
\text { time } \\
(\text { IQR) }\end{array}$ & $\begin{array}{c}\text { CT report to } \\
\text { thrombolysis time } \\
\text { (IQR) }\end{array}$ \\
\hline $\begin{array}{c}\text { Thrombolysis in } \\
\text { ischaemic stroke } \\
\text { (with exclusions) }\end{array}$ & 48 minutes (37.5-49) & 20 minutes (17.5-25) & 21 minutes (13-24.5) \\
\hline
\end{tabular}




\section{University Library}

\section{- M M N E R VA A gateway to Melbourne's research publications}

Minerva Access is the Institutional Repository of The University of Melbourne

Author/s:

Yang, TWW;Islam, MR

Title:

Quality of acute stroke care in a regional Victorian hospital, Australia

Date:

2019-04-01

Citation:

Yang, T. W. W. \& Islam, M. R. (2019). Quality of acute stroke care in a regional Victorian hospital, Australia. AUSTRALIAN JOURNAL OF RURAL HEALTH, 27 (2), pp.153-157. https:// doi.org/10.1111/ajr. 12491.

Persistent Link:

http://hdl.handle.net/11343/285661 